\title{
Crafting Climate Resilience for People at Bottom of Pyramid Using Digital Innovation
}

\author{
Himanshu Verma, Florian Moder, and Zakir Hussain Shaik
}

\begin{abstract}
Indian agriculture sector accounts for 13.9 per cent of India's gross domestic product (GDP) and employs about 54.6 per cent of the country's workforce. ICT tools are common these days to support agriculture sector. Close to 46.000 farm graduates were trained on ICT between 2002 and 2016, more than 19.000 ventures begun till 2016 in this sector and currently 25 Kisan call centers (farmer hotline) are located in different parts of the country utilizing ICT. In spite of so much ICT interventions, farmers are still at bottom of economic and social pyramid in India. The project CCKN-IA (Climate Change Knowledge network in Indian Agriculture implemented by the German Development Cooperation - GIZ) has made an attempt to identify lacunas and multiple needs of the farmers and come up with a unique, innovative and pragmatic idea to bridge the knowledge gap applying state of the art ICT.
\end{abstract}

Index Terms-Agriculture, climate adaptation, ICTs, India, innovations, knowledge network, NICE, open source.

\section{INTRODUCTION}

- India is among bottom 15 countries in the world out of 127 countries list in literacy rate as per 'Education for All Index', as per UNESCO website (http://en.unesco.org/).

- India has the largest number of second-language speakers of English

- 275 million smartphone connections in India by ending June 2016 (259 million in the US), which is still only $1 / 5$ th of total population as per Government of India estimation

- GSMA research says that 616 Mio. GSM subscriber added in India by 2016

Above list shows the diversity of this country, where there is a lot contradiction upon development in the country. The same applies to agriculture as well. The Indian Government has invested a lot of money and efforts to improve agriculture system [1], help farmers to grow more, mitigate Climate Change risk mostly facilitated by ICT tools.

Agriculture in India is experiencing a dramatic increase in the share of total investment in Gross Capital Formation in

Manuscript received May 12, 2017; revised September 2, 2017. This work is part of CCKN-IA project funded by Government of Germany Federal Ministry for Economic Cooperation and Development, GIZ is implementing agency with duration of 48 months (05/2013-04/2017).

H. Verma was with GOPA Consultants, posted in New Delhi, India. He is now with Deutsche Gesellschaft für Internationale Zusammenarbeit (GIZ) GmbH, India (e-mail: h.verma2506@gmail.com).

F. Moder is with Deutsche Gesellschaft für Internationale Zusammenarbeit (GIZ) GmbH (e-mail: florian.moder@giz.de).

Z Hussain was with GOPA Consultants, posted in New Delhi, India. He is now with Ministry of Agriculture, Telangana, India (e-mail: zakiradvisor71@gmail.com). recent years. Although Gross capital formation (GCF) i.e. investment in Agriculture and Allied Sectors relative to GDP in this sector has been showing an upward trend (from 13.5 per cent in 2004-05 to 20.1 per cent in 2010 -11) the farmers are still at bottom of economic and social pyramid in India.

Probable reasons may be as implementers focused largely on developing institutions and developing ICT systems solely, which disconnects direct interaction with farmers. ICT systems are at high advantage when it comes to fast transformation of knowledge to a large scale, but individual interaction is lost. In addition farmers face increasingly the impacts of climate change in form of unrepresented extreme weather events such as unseasonal rainfalls, droughts, and heavy storm events. Only by knowing how can help farmers, implementers and other actors in the sector of agriculture to adapt to these changes.

For example, Maharashtra and Uttar Pradesh are the two states of the country growing the major portion of sugarcane. All the advisories focus on these crops. The content developed is disseminated to all sugarcane farmers in the entire district. The emphasis on other farmers and other crops is less. The service providers send SMS in English and local languages and through voice calls in local language to farmers. This kind of approach may serve the needs of 50 to $60 \%$ farmers but not 100 per cent.

The ground realities are always different, not every farmer in one districts sows sugarcane or tomato at same time, because a district itself is a large entity area wise and every farmer has his own situations, like professionals in any metropolitan cities. For example Frankfurt is the largest financial center on the continent but every citizen of Frankfurt is not a banker or Masters in Finance or economics, there would be IT professionals, Analysts, Traders, Custom relation officers etc..

To solve such discrepancy it requires a complex but simple to use system. Only ICT solutions can resolve this diverse needs at a large scale. NICE is working on same lines.

\section{THE PROJECT}

The project CCKN-IA (Climate change Knowledge network in Indian Agriculture) has made an attempt to address the multiple needs of the farmers involving a pool of experts, providing a unique, innovative and pragmatic ICT platform.

This paper reveals a case study about a project called Climate Change Knowledge Network in Indian Agriculture (CCKN-IA). This is a bilateral project implemented by GIZ and the Indian Ministry of Agriculture. The project has created an innovative open source web solution using 
semantic web technologies, named 'NICE' - Network for Information on Climate (Ex)change. It is currently developed, tested and institutionalized. NICE on web platform allows various knowledge providers from various domains of agriculture science sharing knowledge in a decentralized way across a number of subject domains to address local needs. The system is iterative and allows a multimodal two-way communication, between the expert network and linked farmers' to meet the specific needs on a real time basis. The NICE application is combined with a tablet application capacitating extension cadres to function as last mile technology interface with farmers. The project revitalizes existing extension system, capacitates and monitoring systems for effective development, dissemination and facilitates farmer adoption on extreme weather events.

\section{The EXIsting GAPS IN ICT USE AND Agriculture DEVELOPMENT IN INDIA}

India substantially need an effective knowledge management network to deal with climate change impacts. Indeed the farmers are willing to pay for advisories on climate adaptations [2] but the public and private sector initiatives remained as islands of success without considerable efforts to scale up. Many of these initiatives have not been able to address the specific needs of the farmers, possibly because advisory systems are limited to one-way communication mode [3] without proper institutionalization [4]. Whereas the knowledge on adaptations exist in India, relevant information are scattered across various institutions. To address farmer's local adaptation needs it is necessary to combine this expertise and make it accessible to farmers in real-time. This necessitates revitalizing and setting up an effective and efficient knowledge exchange mechanism, providing a tool to deal with dynamic changes in weather and climatic patterns. Nonetheless different Information and Communication Technology (ICT) projects with different origin and purpose of, related to agricultural development in India [5] are in place and were developed. Their focus is purely limited on improving the delivery mode to the farmers rather than looking at the quality of information itself. The information disseminated is too generic and does not meet the local needs of the farmers [6]. India faces a juxtaposed situation wherein there are areas where farmers do not have any access to information and at the same time they are "spammed" with generic, complex and locally distant advisories. Agriculture extension face the need in the current scenario to respond to rapidly changing conditions. Hence, extensionists who regularly connect with farmers are looking for innovative techniques of information dissemination [7]. Most of the projects do not have collaboration with other farm research and extension stakeholders. Practical challenges or constraints in implementing the ICT projects are seldom disclosed and shared with others. Learning experience of one project to another project is seldom shared [8].Studies reveal that little efforts to refine the knowledge and broad basing with digital solutions is lacking. This situation drove the project to think about on what kind of ICT innovations and institutional designs would effectively help Indian farmers to cope up with the impacts of climate change by adoption, which can only be achieved by addressing the particular farmers situation, considering him as an individual entity instead of treating him as a part of a large group.

\section{A. Strengthening and Building on the Existing Mainstream Agricultural Extension Systems}

CCKN-IA is implemented in various states through a strategic partnership with local State Agriculture Departments. The project has made efforts to establish and strengthen needed institutional systems as in Fig. 1. In each state, the Government mandated agencies like SAMETIs (State Agriculture Management and Training Institutes) have been nominated and function as Consortium Facilitating Agencies (CFA) to efficiently manage the network of experts, extension agents, and farmers. Further, to ensure and support quality of advisories, Content Advisory Groups (CAGs) have been established, represented by senior scientists and practitioners in the State. The project is guided and steered through established National and State level steering committees. At the national level, National Institute of Agriculture Extension and Management (MANAGE), has been assigned the role of National Consortium Facilitating Agency (NCFA). MANAGE not only ensures linkages with national research and other partners to provide updated knowledge but also supports in the strengthening of state-level agencies to mainstream sustainable and climate change adaptation training.

\section{B. The Design and Innovation}

This paper attempts to address all these anomalies and presents a unique and innovative solution in form of institutional arrangements combined with capacity building using ICT. These learnings come from the project namely Climate Change Knowledge Network in Indian Agriculture (CCKN-IA), being implemented in India. We hypothesize that creation of a decentralized knowledge network providing localized and dynamic information can be only achieved by applying ICT along with engagement of human interface as a key for success. The basic objective of CCKN-IA is to create a decentralized knowledge network with diverse expertise on agriculture and related domains, disseminating location specific information through a novel ICT solution. The program has deployed experts from different domains for content generation, validation and dissemination thereby ensuring timely access to quality knowledge across various knowledge domains. The project follows a three-pronged design to develop the capacities for effective exchange of localized need based advisories. Thus, to further scale up and sustain the project, it ensures mainstreaming of innovations. The open source web-based Network for Information on Climate (ex)Change (NICE) integrates multiple knowledge partners with diverse expertise such as meteorology, agriculture science, extension systems etc. The system allows multimodal approach and enables a two-way communication to link farmers' needs to knowledge experts on a real time basis. Besides advisories being sent as SMSs, directly to farmers only in emergency situations, extension agents also use tablets to disseminate advisories to farmers creating a more personal link. Effective knowledge exchange between 
diverse experts and organizations necessitates an operational network of such entities at various tiers. To ensure sustainability of these networks working even beyond project life, the project has identified mandated government institutions like State Agriculture Management and Training Institutes (SAMETIs) at state levels and National Institute for Agriculture Extension Management (MANAGE) at national level as Consortium Facilitating Agency (CFA). Institutions held responsible to coordinate and continue the work with networks of such diverse actors. Similarly, the project also focuses on capacity building of the key stakeholders, frontline extension workers, Government agriculture functionaries and others to improve the quality and efficiency on knowledge exchange.

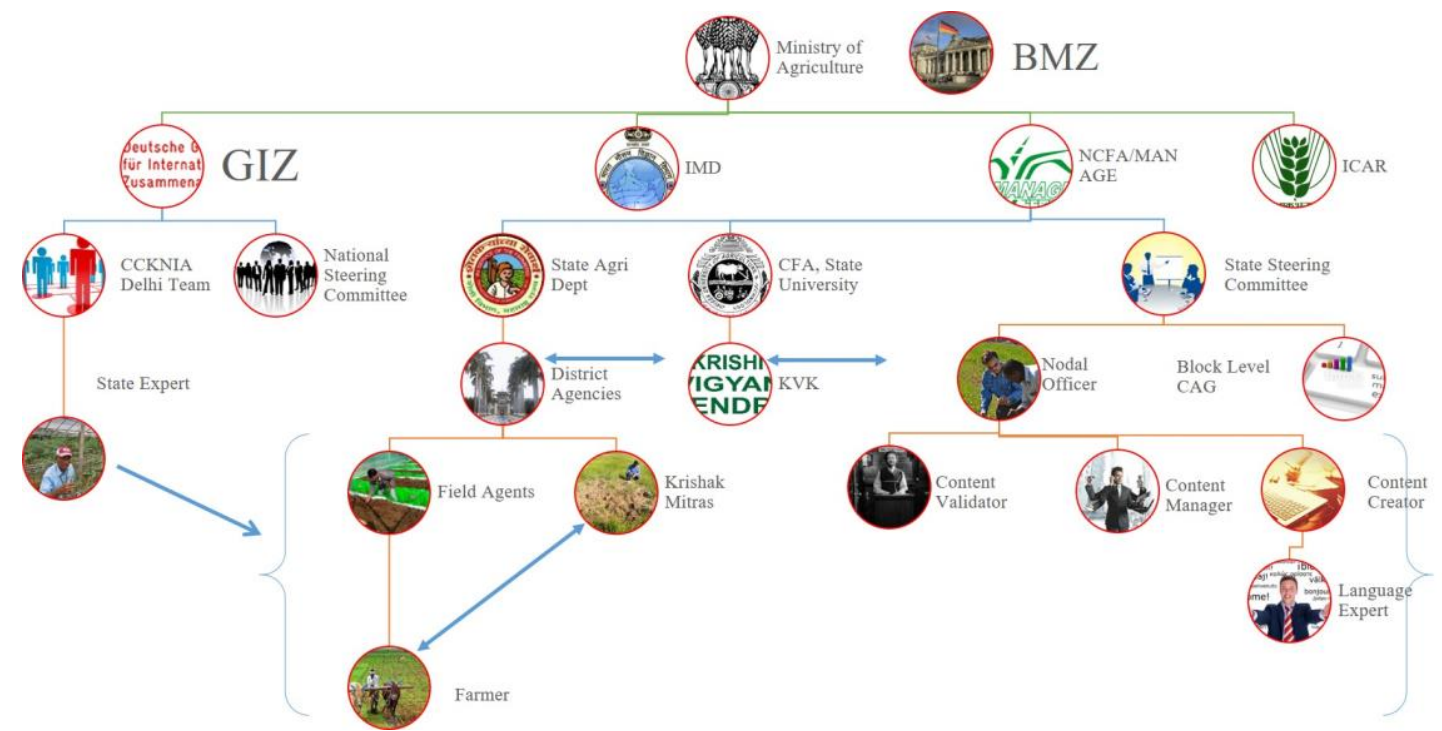

Fig. 1. The institutional framework of CCKN-IA.

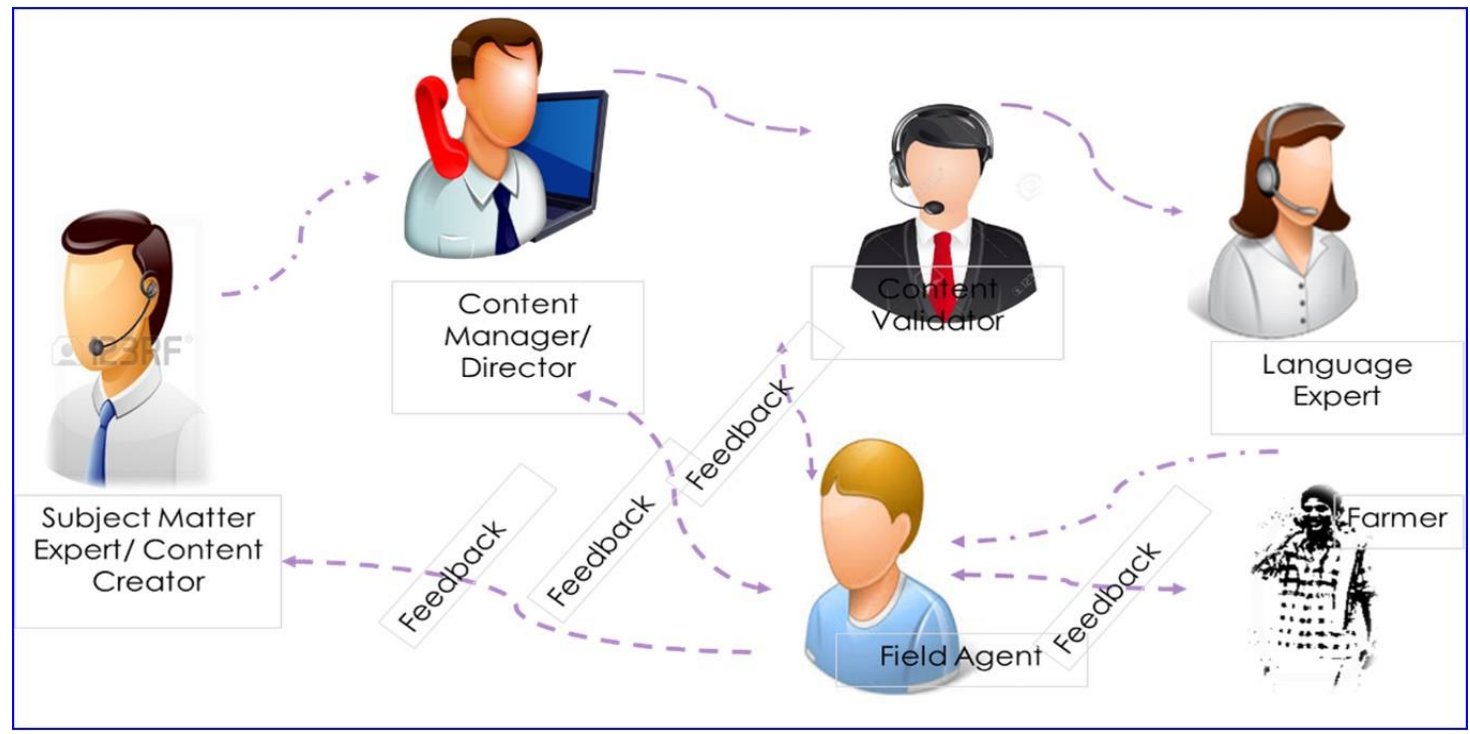

Fig. 2. Content management loop.

\section{The Process of Technology Transfer}

To better ensure quality information, the project has adopted a web based peer-review process starting from content generation to content dissemination as in Fig. 2. Persons assigned to create content are developing domain specific agriculture advisories, considering climate predictions in combination with medium to short-term weather forecasts, provided by the Indian Meteorological Department (IMD), for particular locations. Subject Matter Experts (SMEs) from scientific institutions like State Agriculture Universities validate the content created. SMEs can reject, edit or approve content online. The content is after approval translated into the local language and disseminated. The content manager monitors the entire process from content creation till dissemination and must ensure that the quality parameters are met. The quality norms were jointly developed and are strictly emphasizing on developing content aligned to farmers local needs, technical validity, completeness of the information (to reduce information asymmetry), and understandability (to avoid too generic and too technical information). The semantic web platform decentralizes the content generation and translation cycle. Subsequently the content goes to the frontline extension worker's tablet for dissemination. Extension workers interact with farmers directly by explaining recommended practices and related information accessed through the tablet application. In addition the tablet application enables the extension agents to register farmers and their local contexts such as socio-economic details, details about land holding 
and type of lands, crop to be sown in current or coming crop season, quality of soil, details of livestock and farming equipment and details of loans and memberships in any group or programme on NICE. It is also possible to provide dynamic feedback and needs of farmers to the experts for further iteration and refinement of advisories.

\section{GIS Technology Usage}

In addition the NICE web application uses GeoServer to map important places in pilot villages e.g. Machinery suppliers, Fertilizer, pesticide and seeds suppliers and shops other required items for the villagers and farmers. Relevant details can be sent to farmers through their mobile using NICE dissemination tool.

NICE also maps Hospitals, Storage houses, Government and NGOs created safe locations during any disaster occurrence, these locations can be easily searched on NICE web application to find out required location within a customizable range. The identified details along with the address can be sent to relevant recipients using SMS to inform about nearby relief locations.

TABLE I: NICE COMPONENTS

\begin{tabular}{ll}
\hline \multirow{2}{*}{ Feedback System } & Two way communication from field agents, farmers to experts \\
\cline { 2 - 2 } Query System & This feedback system is done through tablet enabled Mobile app of CCKN-IA \\
\hline Contingency Crop & Farmers with the help of field agents can raise query related to their field problem \\
Plans & $\begin{array}{l}\text { The tablet application of NICE supports this process } \\
\text { suggest next course of action, e.g. change in crop or applying any safety measure. }\end{array}$ \\
\cline { 2 - 2 } User Registration & GIS data- GIS mapping of Input dealers, nearby agro-clinics etc. are available on GIS data of NICE \\
\cline { 2 - 2 } & $\begin{array}{l}\text { Users who use the system have been provided with different roles } \\
\text { any Discipline maintaining same level of Authorisation process. }\end{array}$ \\
\hline Quality Audit & $\begin{array}{l}\text { Entire content on NICE goes through strong audit process, which enables to develop only relevant, } \\
\text { localised and useful content only, helps to create content for any location or language in the country }\end{array}$ \\
\hline $\begin{array}{l}\text { Content is disseminated through various channels and modes such as human interface, SMS, print } \\
\text { material and social media }\end{array}$ \\
\hline
\end{tabular}

\section{E. How NICE Works?}

NICE is an open web application, easy to adopt by any organization. It provides many features which can give an edge to serve rural people specially farmers in various situations (see Table I). NICE is module based and secured with login authorisation (Username/Password). In addition users have to assign to particular roles and functions, according to which a selection of relevant modules will be provided. Provision of modules depended on users roles can be customised on the backend by the administrator. After the user gets authorised he or she can access all functionalities according to the assigned role in the system and start using it though. NICE allows registration of farmer's complete details including his personal information, contact details, family information, livestock and farm related details. For example details about, how much land, which crops, what kind of irrigation system is used, equipment's he has. These information have to be updated from time to time by Field agents on their tablet residing in the villages.

NICE works with a three layered architecture where -Data layer stores the data in database. Whereas the Business logics are handled by "application layer" and the "UI Layer" takes care of passing on user input to the application layer and displaying the results through APIs.

Field agents act as frontline interface of the NICE platform and facilitate the dialogue between the SMEs and farmers. Field Agent update details of farmers, their queries, their feedback about the system and their up-coming activities on NICE Platform.

They support and educate the farmers about the content created by content team, solution to their queries, any government scheme or any farm related problems like livestock etc. The tablet application works also in offline mode since there are still village with no mobile network coverage. Hence, even in absence of network connectivity
Field Agents can access the application with last updated data and update farmer's details as well, and synchronize automatically whenever field agents come in internet coverage.

\section{F. Mobile App}

CCKN-IA has developed a mobile app of NICE web platform through which dissemination of information to farmers is possible via field extension agents using tablets as in Fig. 3. Field agents can create farmers profile in the village, record farmer queries, show disseminated and relevant up to date information to the farmers. They can search content that is relevant to the farmers based on the crop calendar and crop season. Each field assistant is provided with login id and password. They can login, enter the farmer's profile and details about farm operations and crop situations. In case this information still doesn't answer the questions, queries for particular subjects can be posted to the expert network in written and picture format for example about the symptom or disease a crop is showing. This information is sent through the mobile app to the expert network. The expert's assigned to that particular block or district receives a notification on his mobile and email about this query and must answer this within a stipulated time of 24 hrs. through SMS, directly contact to the farmer or message on the NICE App. In addition the field agents can take a printout of the advisories and display them on the display boards installed in a common public place in the village.

\section{G. Capacity Building of Stakeholders and Partners}

To ensure, effective knowledge transfer, CCKN-IA has made conscious efforts to develop the capacities of multitude of experts. This includes a three-pronged approach, i.e. from field orientation of experts before the cropping season to understand local cropping systems and needs coupled with strategies to get near real time feedback and response from 
farmers. Thereby quick reiteration of knowledge and multitier quality norms ensure validity and quality of knowledge created. The experts are oriented on use of NICE to develop and validate knowledge thus created this information once approved by experts is freely available on system's web platform without registration so that as much as possible people get benefitted out of the system. One of the critical components of the project is developing capacities of related organizations such that they are able to effectively perform their role in knowledge exchange as well as effective local decision-making processes. The personnel at Ministry and Department of Agriculture at State level has been trained on using NICE as a tool to access information on progress, outreach and others to enable quick decisions. CCKN-IA works with local mandated training institutions like State Agriculture Management and Extension Training Institutes (SAMETIs) to build their capacities to ensure quality exchange of adaptation knowledge as well as provide trainings on use of ICT and climate change adaptation. In partnership with National Institute of Agriculture Extension Management (MANAGE), CCKN-IA is mainstreaming the capacity building efforts and replicating the approach to other geographies.
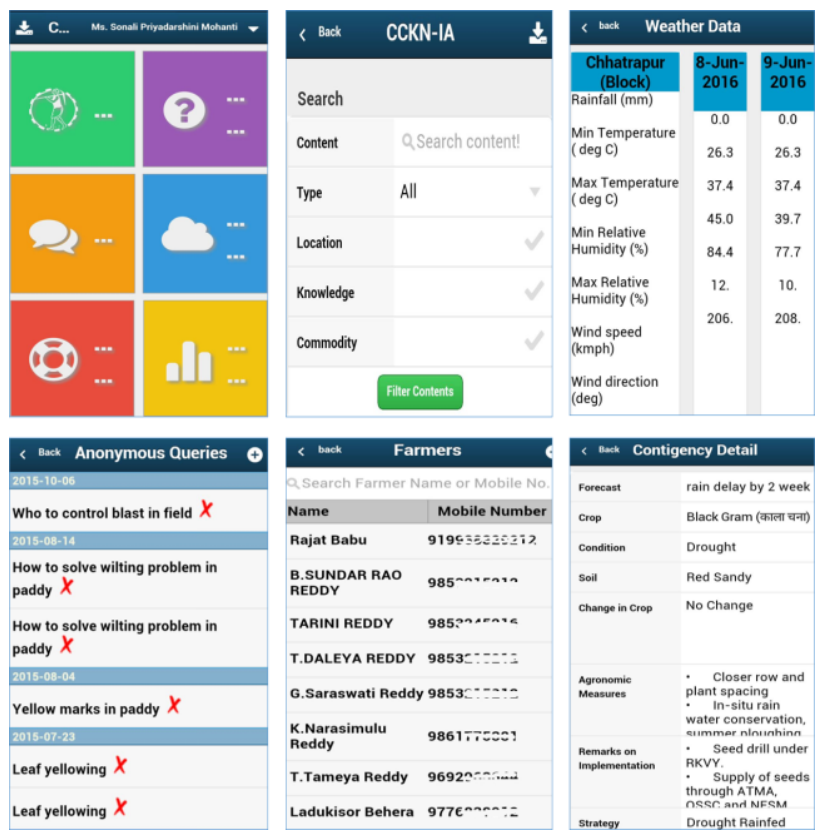

Fig. 3. NICE mobile app.

\section{H. Impacts at a Glance}

CCKN-IA has trained over 100 Subject Matter Experts on generating advisories meeting highest quality standards. To this date, over 350 users including advisory creators, senior subject experts and translators are using NICE to generate quality advisories. In the same manner, the project created cadre of 100 community-based extension service providers not only for effective dissemination of knowledge to farmers using ICT tools but also as a link between farmers and experts. These numbers are growing on a daily basis due to the need of customized and high quality advisories. The project empowered 42 farmers' as experts on pest and disease management so that they can take the role of community extension agents which help farmers to provide knowledge based on their specific needs. So far, nearly 18,200 farmers are actively receiving localized advisories generated through NICE using multimodal dissemination. Government partners have appreciated the innovative system for timely exchange of quality advisories. Institutions like MANAGE has taken the initiative to extend use of NICE. CCKN-IA is still extending functionalities towards a combination of knowledge management in combination with a decision support system. The project is trying to extend user base and broad base the other thematic domains.

The system NICE is continuously upgraded and improving to adapt to different requirements. The system proofed to be a robust system for Knowledge Management and Exchange in rural areas. In a next step it is intended to convert it into an Automated Advisory System where minimal resources are required to serve large number beneficiaries base, providing correct information at the right time without any human/expert intervention required.

\section{CONCLUSION}

If India is considered as a village of 125 people, then only 2 people speaks same language ${ }^{1}$, and 2.5 people belongs to same ethnicity, 62 people are involved in Agriculture and 41 people can read and write Hindi.

In such a diverse nation, it is impossible to help everyone with a "one fits all" solution. The situation is too diverse and hence a highly automated multimodal approach can only work as provided by the NICE system.

NICE is able to handle multiple languages for content creation for multiple domains and bridges the last mile through multiple modes, whether it is on tablets, through SMS, Web, social media communicators or / and facilitates interaction through human interfaces. It is able to aggregate information on weather, climate contextualized agro advisories, disaster relieve and can be customized to any needs. In addition it holds a monitoring and reporting function, through which demand based dynamic reports can be generated.

\section{ACKNOWLEDGEMENT}

This work demonstrates the successful case of the project Climate Change Knowledge Network in Indian Agriculture. We kindly acknowledge the support of Deutsche Gesellschaft für Internationale Zusammenarbeit Gmbh) and Federal Ministry for Economic Cooperation and Development. We are highly thankful to them for their kind support and excellent thought for a project like this. Our heartfelt thanks to Ministry of Agriculture and Rainfed Department, Government of India for their constant support and encouragement in addition to taking the idea to the state and make it happen. Similarly, our thanks to State Departments of Agriculture, Jharkhand, Odisha and Maharashtra for their support and involvement. Our sincere thanks to GOPA consultants for making this project a success being a partner in the project. Our sincere thanks to MANAGE, Hyderabad and SAMETI, Jharkhand, IMAGE,

\footnotetext{
${ }^{1}$ https://en.wikipedia.org/wiki/List_of_languages_by_number_of_native _speakers_in_India major language is which is native to more than 1 Lac people
} 
Odisha and RAMETI, Maharashtra to associate with us as consortium partners. We highly appreciate the association with KVKs, Experts and Universities, ICAR institutes for their constant support and encouragement. Finally yet importantly, we are highly thankful to all farmers and field extension agents who are the main stakeholders in order to make this project a success. State Experts

\section{REFERENCES}

[1] Sajesh and Suresh, "Public-sector agricultural extension in India: A note," Review of Agrarian Studies, vol. 6, no. 1, 2016.

[1] M. Jha, "Farmers welcome mobile info providers for agri-advisory services," Business Line, November 17, 2011, 2011.

[2] A. Jhunjhunwala, J. Rangarajan, and N. Neeraja, "The role of ICT in empowering rural Indians," Social and Economic Effects of Community Wireless Networks and Infrastructures, pp. 75-93, 2013.

[3] V. Ahuja, "Cyber extension: A convergence of ICT and agricultural development," Global Media Journal: Indian Edition 2, vol. 2, p. p1, 2011.

[4] R. Saravanan, "ICTs for agricultural extension," Global Experiments, Innovations and Experiences, New Delhi: New India Pub. Agency, 2010.

[5] M. Surabhi, "Modern ICT for agricultural development and risk management in Smallholder agriculture in India, socioeconomics program working papers," CIMMYT: International Maize and Wheat Improvement Center, 2012

[6] M. Surabhi and M. Mamtha, "How mobile phones contribute to growth of small how mobile phones contribute to growth of small farmers? evidence from India," Quarterly Journal of International Agriculture, vol. 3, pp. 227-244, 2012.

[7] R. Sarvanan, "ICTs for agricultural Extension in India: Policy implications for developing countries," 2012.

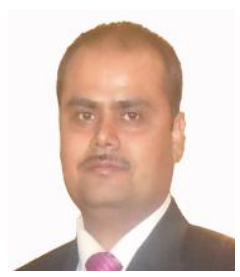

Himanshu Verma was born on June 25, in Delhi, India. He got the masters in information technology, Allahabad Agriculture Institute Deemed University, Allahabad, Uttar Pradesh, India, 2006.

Mr. Himanshu has over 12 years of work experience in information technology field. Currently he is working as National ICT advisor for Climate Change Project under Indo-German collaboration in India, worked as Project Manager and Business analyst for national level project in Agriculture and Health department funded by various international donor organisations, worked for CABI, DFID respectively in Agriculture and Health procurement projects.

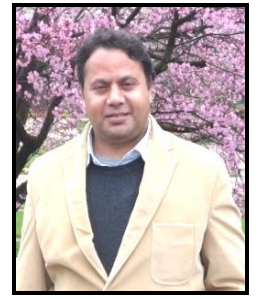

Zakir Hussain belongs hyderabad, India and currently he is based in Bhubaneswar, Odisha, India. He holds the doctor of philosophy (Ph.D.),

Dr. Zakir is an agricultural development expert with more than 15 years of experience in managing various development projects in India. He coordinated a large scale scaling up project called community managed sustainable agriculture in the initial take off phase in A.P., India. The major area of work includes scaling up of sustainable agriculture models through networking with Government and NGOs. Ample experience in documenting best practices and sharing them in various national and international platforms.

Dr. Hussain has profound experience in livelihoods, value chain and building farmer's institutions. In the past decade he has extensively worked on capacity building of farmers and eventually created a barefoot cadre of farmer resource farmers.

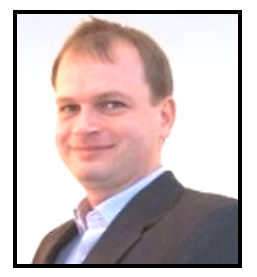

Florian Moder based in New Delhi, India. He holds a master in geoinformatics and forestry engineering. $\mathrm{He}$ is working as technical advisor for the GIZ India since 2013 with the CCKN-IA project. From 2009 till 2013 he supported as an integrated expert (CIM) the WISDOM project (conducted by the German Aerospace Center - DLR) in Vietnam to establish a water information system for the Mekong Delta. Mr. Moder overall experience is in designing and implementing information systems is based on his consultancy works in the field of remote sensing and GIS from 2005 to 2009. 